\title{
Tumoral CD105 is a novel independent prognostic marker for prognosis in clear-cell renal cell carcinoma
}

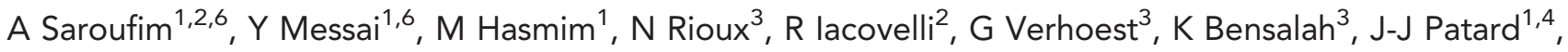 \\ L Albiges $^{1,2}$, B Azzarone ${ }^{5}$, B Escudier ${ }^{1,2}$ and S Chouaib*,1 \\ ${ }^{1}$ INSERM U753, Institut Gustave Roussy, 114 Rue Edouard Vaillant, 94800 Villejuif, France; ${ }^{2}$ Medical Oncology department, Institut \\ Gustave Roussy, 114 Rue Edouard Vaillant, 94800 Villejuif, France; ${ }^{3}$ Department of Pathology, Pontchaillou Hospital, 2 rue Henri Le \\ Guilloux, 35033 Rennes, France; ${ }^{4}$ Urologic Department, Kremlin-Bicêtre Hospital, 78 rue de General Leclerc, 94275 Le Kremlin \\ Bicêtre, France and ${ }^{5}$ Department of Immunology, Istituto Giannina Gaslini, 16100 Genova, Italy
}

Background: Angiogenesis is essential for tumour growth and metastasis. There are conflicting reports as to whether microvessel density (MVD) using the endothelial marker CD105 (cluster of differentiation molecule 105) in clear-cell renal cell carcinomas (ccRCC) is associated with prognosis. Recently, CD105 has been described as a RCC cancer stem cell marker.

Methods: A total of 102 ccRCC were analysed. Representative tumour sections were stained for CD105. Vascularity (endothelial CD105) was quantified by MVD. The immunohistochemistry analysis detected positive (if present) or negative (if absent) CD105 tumoral staining. This retrospective population-based study was evaluated using Kaplan-Meier method, $t$-test and Cox proportional hazard model.

Results: We found that the expression of endothelial CD105 (MVD) negatively correlated with nuclear grade $(P<0.001)$, tumour stage $(P<0.001)$ and Leibovitch score $(P<0.001)$, whereas the expression of tumoral CD105 positively correlated with these three clinicopathological factors $(P<0.001)$. In multivariate analysis, tumoral CD105 was found to be an independent predictor of poor overall survival $(P=0.002)$.

Conclusions: We have shown for the first time that tumoral CD105 is an independent predictive marker for death risk and unfavourable prognosis in patients with ccRCC after curative resection.

Renal cell carcinomas account for 3\% of adult malignancies (Cohen and McGovern, 2005). They are characterised by resistance to conventional anticancer therapies, and often diagnosed at metastatic stages (Flanigan et al, 2004; Cohen and McGovern, 2005).

To date, the assessment of prognosis for RCC patients relies mainly on clinical parameters such as Fuhrman grades (Fuhrman et al, 1982) and stages $(3,4)$. However, these parameters are not entirely reliable (Minardi et al, 2005). Therefore, identifying better prognosis factors is needed for more accurate RCC prognosis.

CD105 (cluster of differentiation molecule 105)/endoglin is a cell transmembrane glycoprotein and a key component of transforming growth factor- $\beta$ receptor complex (Gougos and Letarte, 1990; Derynck and Feng, 1997). It is mainly expressed by angiogenic endothelial cells and has been correlated with tumour microvessel density (MVD) (Kumar et al, 1996; Minhajat et al, 2006; Dallas et al, 2008). Consequently, CD105 has been studied as a potential prognosis factor in RCC with contradictory results (Sandlund et al, 2006; Dubinski et al, 2012).

Recently, tumoral CD105 has been described as a new RCC cancer stem cell (CSC) marker (Bussolati et al, 2008). In fact, a subpopulation expressing membrane CD105 was isolated and it presented CSC characteristics (clonogenicity, expression of stem

\footnotetext{
*Correspondence: Dr S Chouaib; E-mail: chouaib@igr.fr
}

${ }^{6}$ These authors contributed equally to this work.

Received 11 September 2013; revised 13 December 2013; accepted 16 January 2014; published online 4 March 2014 
cell markers and tumour initation capability). Cancer stem cell markers in solid tumours being associated with tumour progression (Hermann et al, 2010), we asked whether tumoral CD105 could have a prognosis value in RCC.

Therefore, we evaluated by immunohistochemistry the relationship between CD105 expression in endothelial and tumoral cells with stages, grades, Leibovitch score (LS) and survival in clear-cell RCC (ccRCC) patients.

\section{MATERIALS AND METHODS}

Patients. Between March 2006 and January 2009, 102 consecutive cases of partial/radical nephrectomy for ccRCC were enroled in a retrospective study. They were obtained from Pontchaillou Hospital (Rennes, France). Informed consent to data and specimen analysis were obtained from all patients for ethical issues. Each tumour was graded based on Fuhrman grading system and staged according to the pTNM 2009 classification system. The follow-up of patients after nephrectomy consisted of physical examination and imaging tests every 4-6 months for non-metastatic patients (M0) and every 2 to 3 months for metastatic patients (M1).

Immunohistochemical staining. Tumour samples were obtained from formalin-fixed and paraffin-embedded surgical specimens. After deparaffinisation, rehydration and blocking of endogenous peroxidase activity, immunohistochemical staining was performed using a monoclonal mouse anti-human CD105 antibody (Kit OMniMAP, Abcam, Paris, France; dilution 1:100). The immunostaining was performed on the selected paraffin bloc corresponding to the highest Fuhrman grade. The expression of CD105 in tumour cells was recorded as negative (absence of staining) or positive (presence of staining). Microvessel density (MVD) is the measurement of the number of vessels per $\mathrm{mm}^{2}$. It was used to evaluate the expression of CD105 in endothelial cells. It was recorded in tertiles as low $\left(1 ; 35-240\right.$ vessels per $\left.\mathrm{mm}^{2}\right)$, moderate $\left(2 ; 241-815\right.$ vessels per $\left.\mathrm{mm}^{2}\right)$ and high $\left(3 ; \geqslant 816\right.$ vessels per $\left.\mathrm{mm}^{2}\right)$. In non-tumoral kidney tissue, there was no staining in tubules, but there was staining in all endothelial cells located in all arteries, tubule capillaries and glomerular endothelial cells.

Statistical analyses. The correlation between CD105 expression and tumour stage, grade and LS was evaluated by the nonparametric Spearman rank test. The $t$-test was used to assess if CD105 expression differs significantly between groups.

The LS is a validated histological scoring algorithm in ccRCC for disease-free survival (DFS) after the nephrectomy in M0. It takes into account the primary tumour status (pathological T stage), the regional lymph node status, the tumour size, the nuclear grade and the presence of histological tumour necrosis. Patients with M0 disease at diagnosis were divided into three risk groups based on the Leibovitch prognostic score. Risk groups were defined as low (scores 0-2), intermediate (scores 3-5) and high $(\geqslant 6)$, respectively.

Disease-free survival was defined as the time from surgery to the first documentation of tumour relapse (local relapse or/and distant metastasis). Overall survival (OS) was defined as the time from surgery to death or last contact. The DFS and OS were estimated using Kaplan-Meier method with 95\% confidence intervals (CI) and compared across the groups using the log-rank test.

Based on the CD105 expression in endothelial cells (MVD), patients were divided into three groups or tertiles: (low (1; $35-240$ vessels per $\left.\mathrm{mm}^{2}\right)$, moderate $\left(2 ; 241-815\right.$ vessels per $\left.\mathrm{mm}^{2}\right)$ and high $\left(3 ; \geqslant 816\right.$ vessels per $\left.\left.\mathrm{mm}^{2}\right)\right)$. For each tertile, OS and DFS were evaluated and compared as described above. In tumour cells, patients were divided into two groups based on the presence or absence of CD105 staining. For each group, OS and DFS were evaluated.
Univariate and multivariate Cox proportional hazard models were fit to determine the clinical and pathological variables that were associated with OS and DFS. Analyses were performed separately for endothelial CD105 (three groups or tertiles) and for tumoral CD105 (two groups). The variables evaluated for OS were age, sex, stage (I-III vs IV), endothelial CD105 expression and tumoral CD105 expression. The variables for DFS were age, sex, LS, endothelial CD105 expression and tumoral CD105 expression. The multivariate model was performed using a stepwise selection approach with type I error of 0.05 for model entry and 0.10 for elimination. Additional elimination was applied to identify significant variables at the level of $P<0.05$. We used PASW (Predictive Analytics SoftWare) (v 19; IBM SPSS, Armonk, NY, USA).

\section{RESULTS}

Patient characteristics. Patient characteristics are summarised in Figure 1A. The median age of patients was 62.2 years. Fifteen patients had metastatic disease (Stage IV) and 87 had nonmetastatic disease (Stage I-III). Forty-two patients had low-nuclear grade (grades 1 and 2), whereas 60 patients had high-nuclear grade (grades 3 and 4). Five patients had lymph node metastasis and 45 patients had tumoral histological necrosis. The median tumour size was $6.2 \mathrm{~cm}$. Twenty-four patients had renal venous invasion. As a clinical parameter, the ECOG (Eastern cooperative Oncology Group) Performance Status (PS) was 0 for 70 patients and 1 for 32 patients. None of the patients of this cohort had ECOG PS $>1$. Five M0 received adjuvant treatment and M1 patients received an antiangiogenic therapy as first-line treatment. Median follow-up was 52 months (4-90 months). In M0 (stages I-III), the median OS was not reached while it was 29.3 months (95\% CI, 0-59.7) in M1 patients (stage IV; Figure 1B). The proportion of patients alive at 5 years was $78 \%$ and $39 \%$ in $\mathrm{M} 0$ and $\mathrm{M} 1$, respectively $(P=0.001$; Figure $1 \mathrm{~B})$. Based on tumour grade, patients were divided into low grade (G1 and G2) and high grade (G3 and G4). The proportion of patients alive at 5 years was $90 \%$ for low grade compared with $65 \%$ for high grade $(P=0.001$; Figure $1 C)$. In the M0 population, the DFS at 5 years for the three Leibovitch risk groups were $96 \%, 76 \%$ and $42 \%$ for low, intermediate and high risk, respectively $(P<0.001)$ (Data not shown).

Endothelial CD105 expression. Endothelial CD105 expression was evaluated by immunohistochemistry using MVD measure. As shown in Figure 2A, tumours were classified into three groups depending on the number of vessels (endothelial cells) positive for the CD105 antibody: low (1; 35-240 vessels per $\mathrm{mm}^{2}$; Figure 2A(1)), moderate $\left(2 ; 241-815\right.$ vessels per $\mathrm{mm}^{2}$; Figure $\left.2 \mathrm{~A}(2)\right)$, and high $\left(3 ; \geqslant 816\right.$ vessels per $\mathrm{mm}^{2}$ ) MVD (Figure $\left.2 \mathrm{~A}(3)\right)$. The number of patients in each group was 34,33 and 35 , respectively.

We next analysed the correlation between endothelial CD105 expression (MVD) and tumour stage, nuclear grade and LS. The median value of MVD was 410 vessels per $\mathrm{mm}^{2}$ (35-1.225). For tumoral stages, the mean value of MVD was 586 vessels per $\mathrm{mm}^{2}$ in M0 (stage I-III) and 198 vessels per $\mathrm{mm}^{2}$ in M1 patients (stage IV). For nuclear grades, the mean value of MVD was 821 for grade 1, 749 for grade 2, 420 for grade 3 and 289 for grade 4 . For Leibovitch risk groups in the M0 cohort, the mean value of MVD was 770, 463 and 350 for low, intermediate and high risk, respectively. In the entire cohort (M1 and M0), high MVD was significantly correlated with low-grade ccRCC $\left(\mathrm{r}_{\mathrm{s}}=-0.503 ; P<0.001\right)$ and early stages (pT1 and pT2) $\left(\mathrm{r}_{\mathrm{s}}=-0.521 ; P<0.001 ;\right.$ Figure $\left.2 \mathrm{~B}\right)$. In the M0 cohort, high MVD was significantly correlated with lower risk Leibotich score $(P<0.001$; Figure 2B).

We further analysed patient survival according to MVD. Based on the three MVD tertiles or groups, the proportion of patients alive 


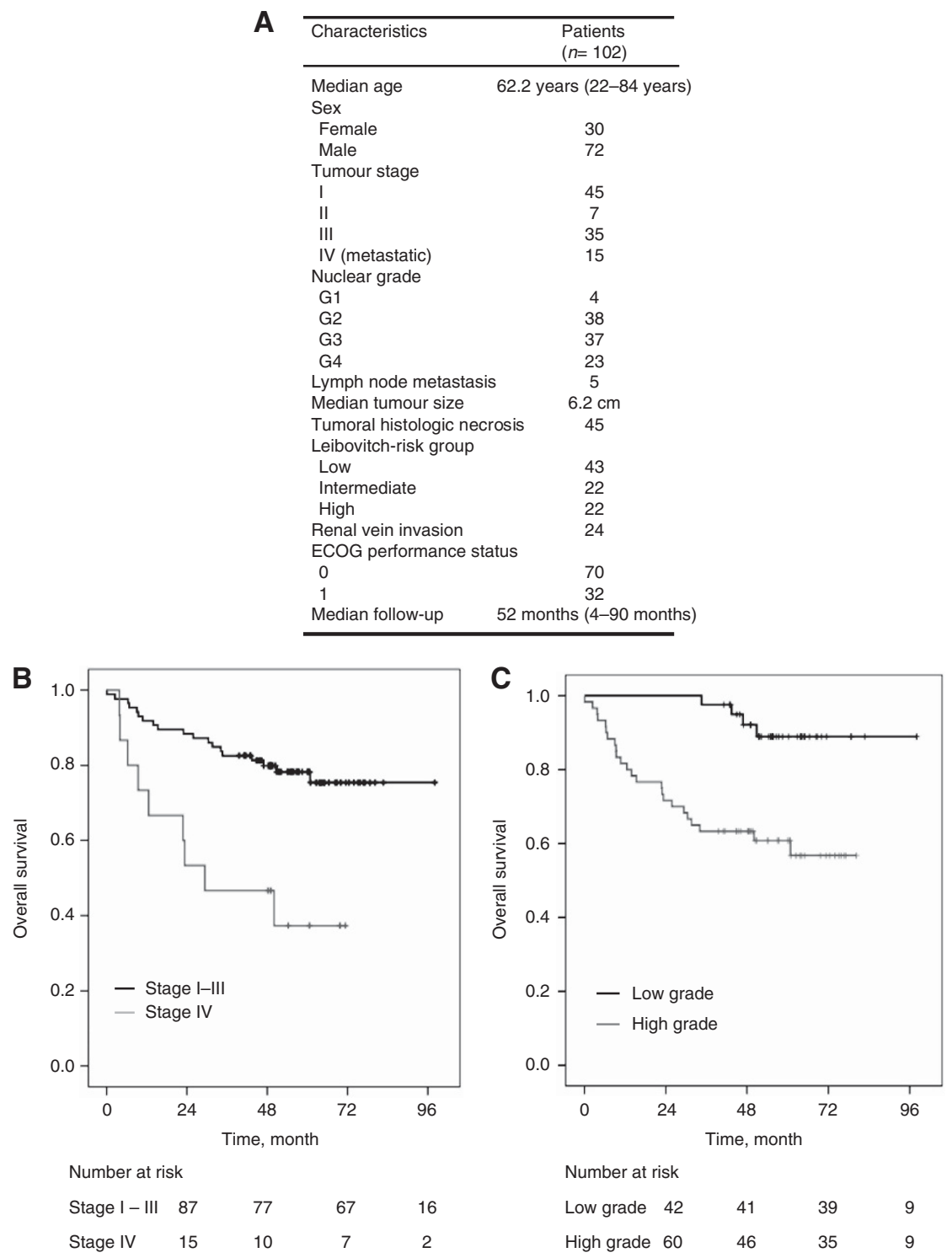

Figure 1. Patient characteristics. (A). Patient characteristics (B). Overall survival of stage I-III patients versus stage IV patients (C). Overall survival of low-grade patients versus high-grade patients.

(OS) at 5 years in the M0 population was $58 \%, 78 \%$, and $91 \%$ for the first, second, and third tertiles, respectively $(P=0.001$; Figure $2 \mathrm{C})$.

On the basis of the MVD tertiles, the proportion of patients alive without disease recurrence (DFS) at 5 years in the M0 population was $56 \%, 71 \%$ and $87 \%$ for the first, second and third tertiles, respectively $(P=0.008$; Figure $2 \mathrm{D})$.

Tumoral CD105 expression. The expression of CD105 in tumour cells was recorded by immunohistochemistry as negative (Figure $3 \mathrm{~A}(1)$ ) or positive (Figure $3 \mathrm{~A}(2)$, (3) and (4)). Positive CD105 staining was detected in the cytoplasm of isolated tumour cells in 29 patients. For each of these cases, the staining was strong and cytoplasmic. It was observed in a few tumour cells (Figure $3 \mathrm{~A}(3)$ ) or in clustered tumour cells (Figure 3A(4)).

In the entire cohort (M1 and M0), the presence of tumoral CD105 staining was directly related to high tumour grade $\left(\mathrm{r}_{\mathrm{s}}=0.642 ; \quad P<0.001\right)$ and to the highest tumour stage $\left(r_{s}=0.505 ; P<0.001\right.$; Figure $\left.3 B\right)$. Moreover, in the M0 population, it was found to be directly related to high Leibovich risk group $\left(r_{s}=0.56 ; P<0.001\right.$; Figure $\left.3 \mathrm{~B}\right)$. Four of the five patients with lymph node metastasis had positive CD105 tumoral staining.
Survival analysis was performed based on positive or negative CD105 tumoral staining. In the entire cohort (M0 and M1), the OS at five years was $39 \%$ and $84 \%$ in positive and negative groups, respectively $(P<0.001)$. In $\mathrm{M} 0$, the median of OS was 60.8 months in patients with tumoral C105 expression, whereas it was not reached in patients without expression of tumoral CD105 $(P=0.001$; Figure 3C).

In M0, the median DFS of positive group (positive CD105 tumoral staining) was 21.5 months, whereas it was not reached in the negative group $(P<0.001$; Figure 3D).

Univariate and multivariate analyses. The univariate analysis highlighted the prognostic value of the tumoral stage for the risk of death $(P=0.001$; Tables 1 and 2$)$. However, the tumoral stage had marginal statistical significance for OS $(P=0.075$ with endothelial CD15 and $P=0.066$ with tumoral CD105) in the multivariate analysis (Tables 1 and 2). The LS had a prognostic value for the risk of disease recurrence after nephrectomy in both univariate $(P<0.001)$ and multivariate analyses $(P<0.001$ with endothelial CD105 and $P=0.002$ with tumoral CD105; Tables 1 and 2). 

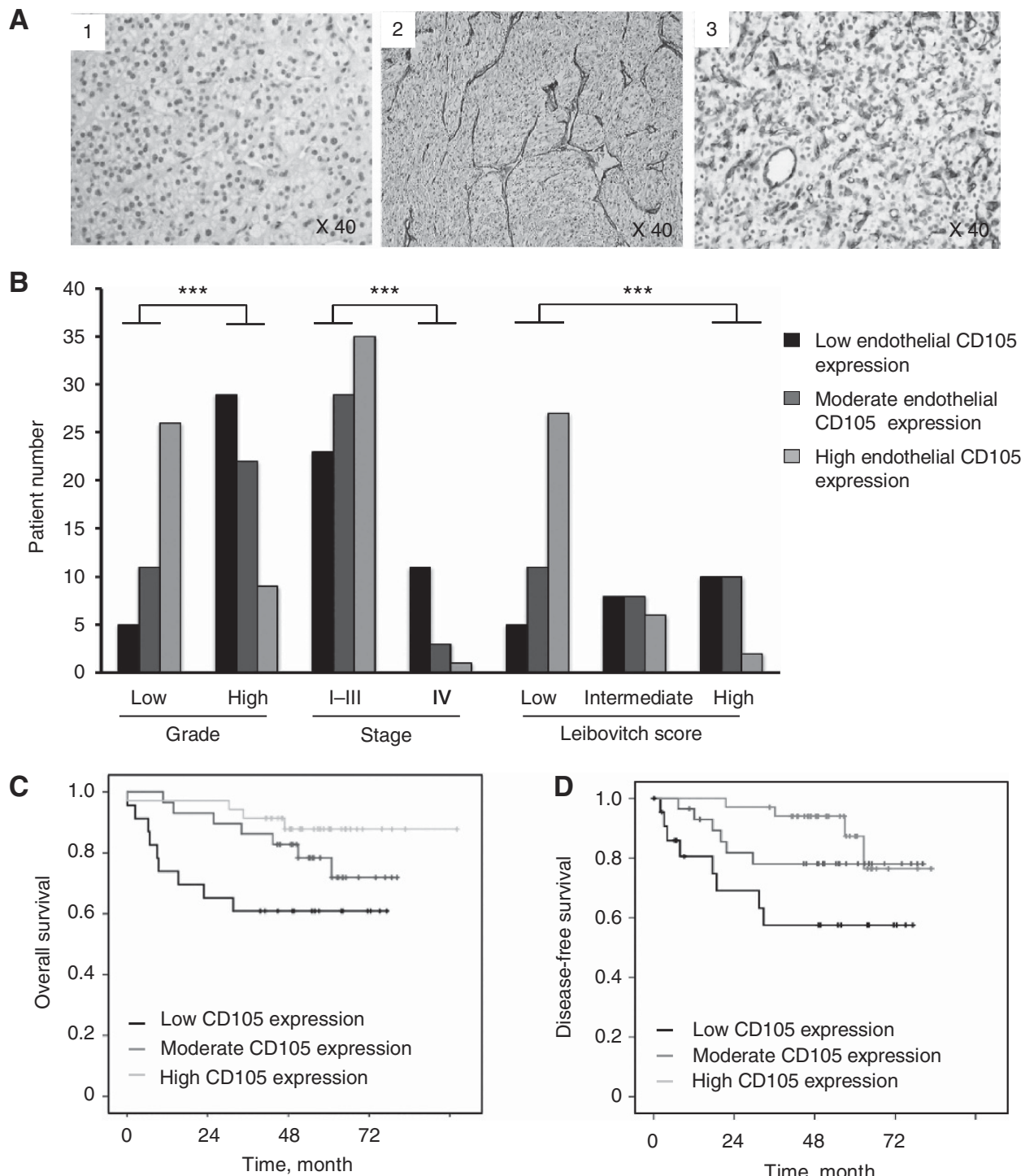

Number at risk

$$
\begin{array}{r}
23 \\
-\quad 29 \\
-\quad 35
\end{array}
$$

$\begin{array}{lll}15 & 11 & 3 \\ 27 & 22 & 4 \\ 34 & 23 & 4\end{array}$

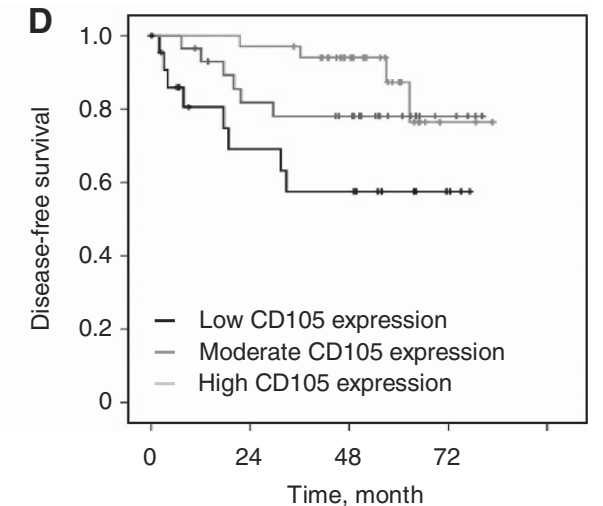

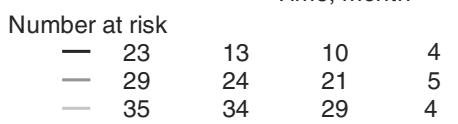

Figure 2. Endothelial CD105 expression. (A). Representative examples of (1) low-, (2) moderate- and (3) high-immunohistochemistry expression of endothelial CD105 on tumoral tissues. (B). Associations of endothelial CD105 expression and tumour characteristics (grade, stage and Leibovitch) in the entire cohort. (C-D). Kaplan-Meier estimates of 5-year OS (C) and DFS (D) according to endothelial CD105 expression in non-metastatic patients. ${ }^{\star \star \star} P<0.001$.

To evaluate the importance of endothelial CD105 expression and tumoral CD105 expression in DFS and OS, univariate analysis was performed.

Both endothelial and tumoral CD105 were found to be prognostic factors for OS $(P<0.001$ for both endothelial and tumoral CD105) and for DFS $(P=0.01$ for endothelial CD105 and $P<0.001$ for tumoral CD105; Tables 1 and 2).

To examine the independent prognostic significance of these molecular variables, multivariate analysis was performed. High expression of endothelial CD105 was revealed as an independent prognostic factor for increased OS ( $\mathrm{HR}=0.48,95 \% \mathrm{CI}=0.28-0.85$; $P=0.011)$. In contrast, it was not an independent prognostic factor for DFS $(P=0.224$; Table 1$)$.

In the multivariate analysis, the tumoral CD105 expression increased the risk of death by more than three times $(\mathrm{HR}=3.76$, 95\% $\mathrm{CI}=1.63-8.66 ; P=0.002)$, and is associated with shorter DFS with marginal statistical significance $(\mathrm{HR}=2.82,95 \% \mathrm{CI}=0.99-8.05$;
$P=0.053$; Table 2). These results show the independent prognostic value of tumoral CD105 expression.

\section{DISCUSSION}

RCC are characterised by their hypervascularity and their particular angiogenic microenvironment (Sudarshan et al, 2013). Therefore, the first-line treatment in metastatic ccRCC is antiangiogenic therapy, targeting vascular endothelial growth factor (VEGF) and/or VEGF pathway (Albiges et al, 2011); (Eisen et al, 2012). RCC are also characterised by unpredictable prognosis (4). Indeed, clinical parameters such as Fuhrman grade and stage are not sufficient for prognosis (Volpe and Patard, 2010). For instance, a low-grade and early-stage tumour can relapse or/and metastasise after surgery. This emphasises the importance 

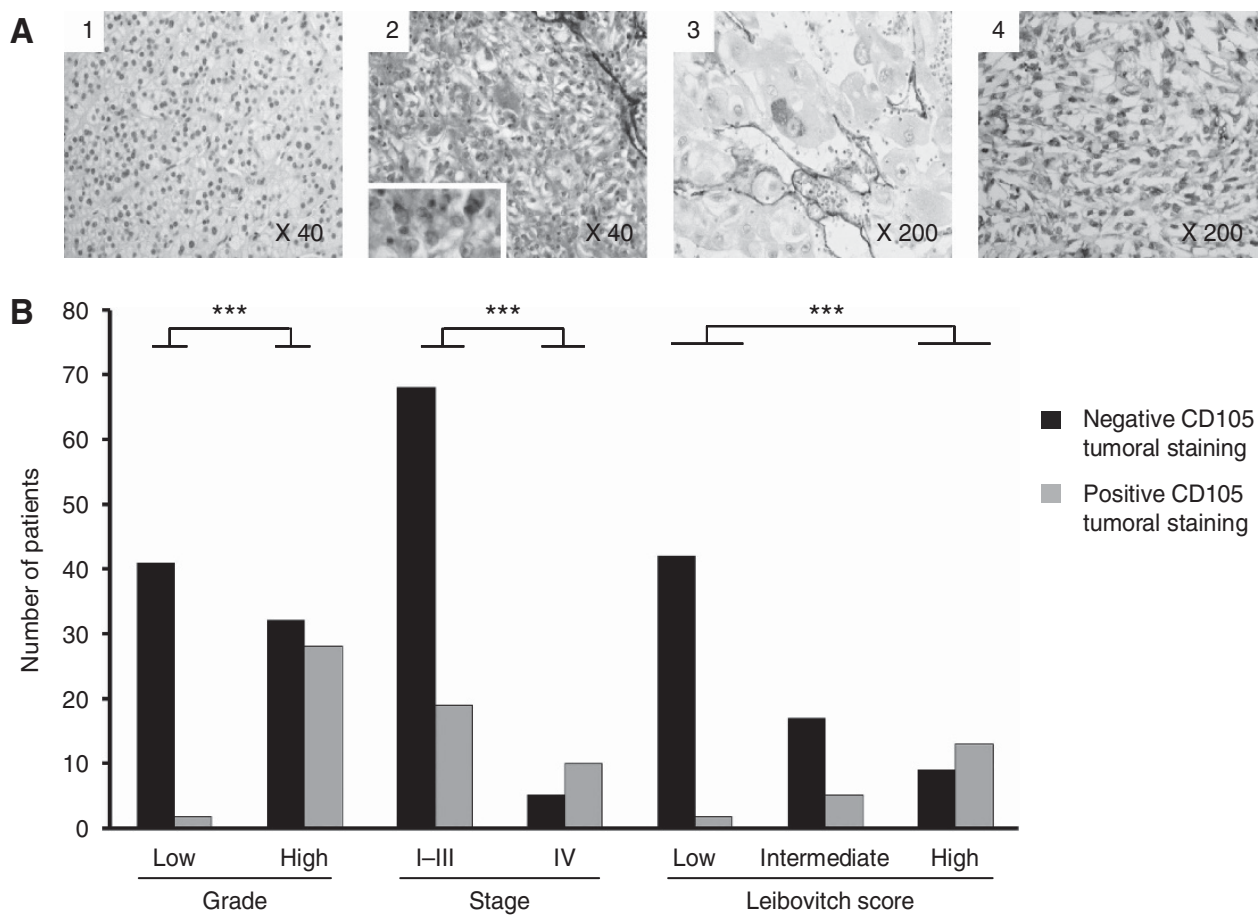

Negative CD105 tumoral staining

Positive CD105 tumoral staining

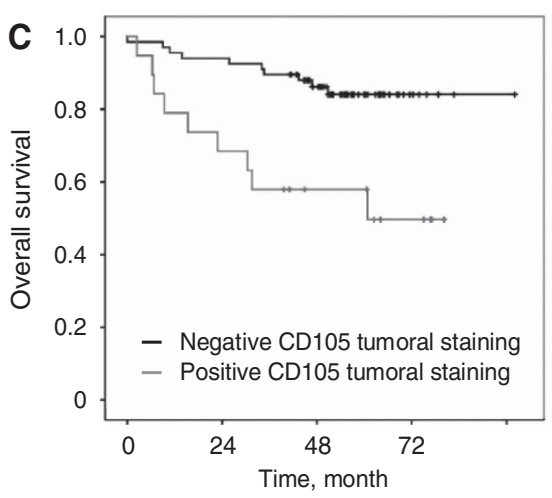

Number at risk

$\begin{array}{cccc}-68 & 63 & 48 & 7 \\ -19 & 13 & 8 & 4\end{array}$

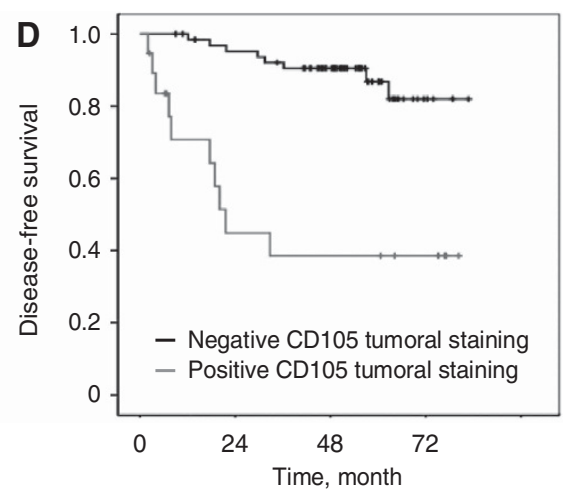

Number at risk

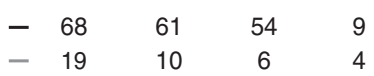

Figure 3. Tumoral CD105 expression. (A). Immunohistochemical images of four cases with tumours denoted as having (2-3-4) tumoral CD105 or not (1). (B). Correlations between the presence of tumoral CD105 by immunochemistry and tumor characteristics (grade, stage and Leibovitch) in the entire cohort. (C-D). Kaplan-Meier estimates of 5-year OS (C) and DFS (D) according to the presence or the absence of tumoral CD105 in non-metastatic patients. ${ }^{\star \star \star} P<0.001$

of searching for alternative or complementary indicators directly related to tumour dissemination within the primary tumours. In the current study, we focused on CD105 protein expression and its prognosis value in the most frequent histologic RCC subtype namely ccRCC.CD105/endoglin is an angiogenic marker (Duff et al, 2003) and has been recently reported to be a CSC marker in ccRCC.The expression of CD105 in endothelial cells could signal future metastasis (Li et al, 2000) but the CD105 expression on tumour cells in ccRCC has no biological value/significance as yet. The relationships between the expression of CD105 and the clinicopathological features of ccRCC are investigated by our group.

Our data indicate that CD105 expression in endothelial cells (Vermeulen et al, 1996) was inversely correlated with clinicopathological parameters. In fact, MVD scores were significantly inversely correlated to Fuhrman nuclear grade, tumour stage and LS. In addition, both disease-free and OS rates of patients with high endothelial CD105 expression (MVD) were significantly higher than those for patients with low MVD (first tertile>second tertile $>$ third tertile). A clear association between high vascularity and favourable prognosis was found in this patient cohort. In the multivariate analysis, endothelial CD105 expression retained independent prognostic significance for $\mathrm{OS}(\mathrm{HR}=0.48,95 \%$ $\mathrm{CI}=0.28-0.85 ; P=0.011)$. Furthermore, we showed for the first time, his prognostic significance with the LS. Our results are consistent with those of previous studies in ccRCC (Sandlund et al, 2006; Yagasaki et al, 2003). It should be noted, however, that an increased CD105 MVD was reported by others to be associated with advanced pathological stage and poor clinical outcome in several types of cancer (Wikstrom et al, 2002; Bochner et al, 1995; Weidner et al, 1991). This inverse relationship in ccRCC could be due to MVD correlation with tumour fibrosis and the development of large-diameter vessels in ccRCC (Delahunt et al, 1997).

The tumoral stage is known to be an independent prognostic factor. In our study, we found a significant statistical difference between tumoral stages (M0 vs M1) and the OS $(P=0.001)$ in the 
Table 1. Evaluation of prognostic role of endothelial CD105 on OS and DFS in univariate and multivariate analyses

\begin{tabular}{|c|c|c|c|c|c|c|}
\hline & \multicolumn{3}{|c|}{ Crude estimates } & \multicolumn{3}{|c|}{ Adjusted estimates } \\
\hline & HR & $(95 \% \mathrm{Cl})$ & $P$-value & HR & $(95 \% \mathrm{Cl})$ & $P$-value \\
\hline \multicolumn{7}{|l|}{ OS in all cohort (Patients $n=102$ ) } \\
\hline $\begin{array}{l}\text { Age } \\
\text { Sex (M/F) } \\
\text { Stage (M1/M0) } \\
\text { CD105 tertiles (3rd/2nd/1st) }\end{array}$ & $\begin{array}{l}1.01 \\
1.72 \\
3.81 \\
0.41\end{array}$ & $\begin{array}{l}0.98-1.04 \\
0.70-4.24 \\
1.71-8.45 \\
0.25-0.69\end{array}$ & $\begin{aligned} & 0.71 \\
& 0.24 \\
& 0.001 \\
&<0.001\end{aligned}$ & $\begin{array}{l}2.19 \\
0.48\end{array}$ & $\begin{array}{l}0.92-5.20 \\
0.28-0.85\end{array}$ & $\begin{array}{l}0.075 \\
0.011 \text { * }\end{array}$ \\
\hline \multicolumn{7}{|l|}{ DFS (Patients $n=87$ ) } \\
\hline $\begin{array}{l}\text { Age } \\
\text { Sex (M/F) } \\
\text { Leibovich risk groups (Low/intermediate/high) } \\
\text { CD105 Tertiles (3rd/2nd/1st) }\end{array}$ & $\begin{array}{l}1.02 \\
2.73 \\
4.23 \\
0.46\end{array}$ & $\begin{array}{l}0.98-1.05 \\
0.79-9.46 \\
2.19-8.17 \\
0.25-0.83\end{array}$ & $\begin{array}{r}0.44 \\
0.11 \\
<0.001 \\
0.010\end{array}$ & $\begin{array}{l}3.84 \\
0.65\end{array}$ & $\begin{array}{l}1.93-7.62 \\
0.33-1.30\end{array}$ & $\begin{array}{c}<0.001^{*} \\
0.224\end{array}$ \\
\hline
\end{tabular}

Table 2. Evaluation of prognostic role of tumoral CD105 on OS and DFS in univariate and multivariate analyses

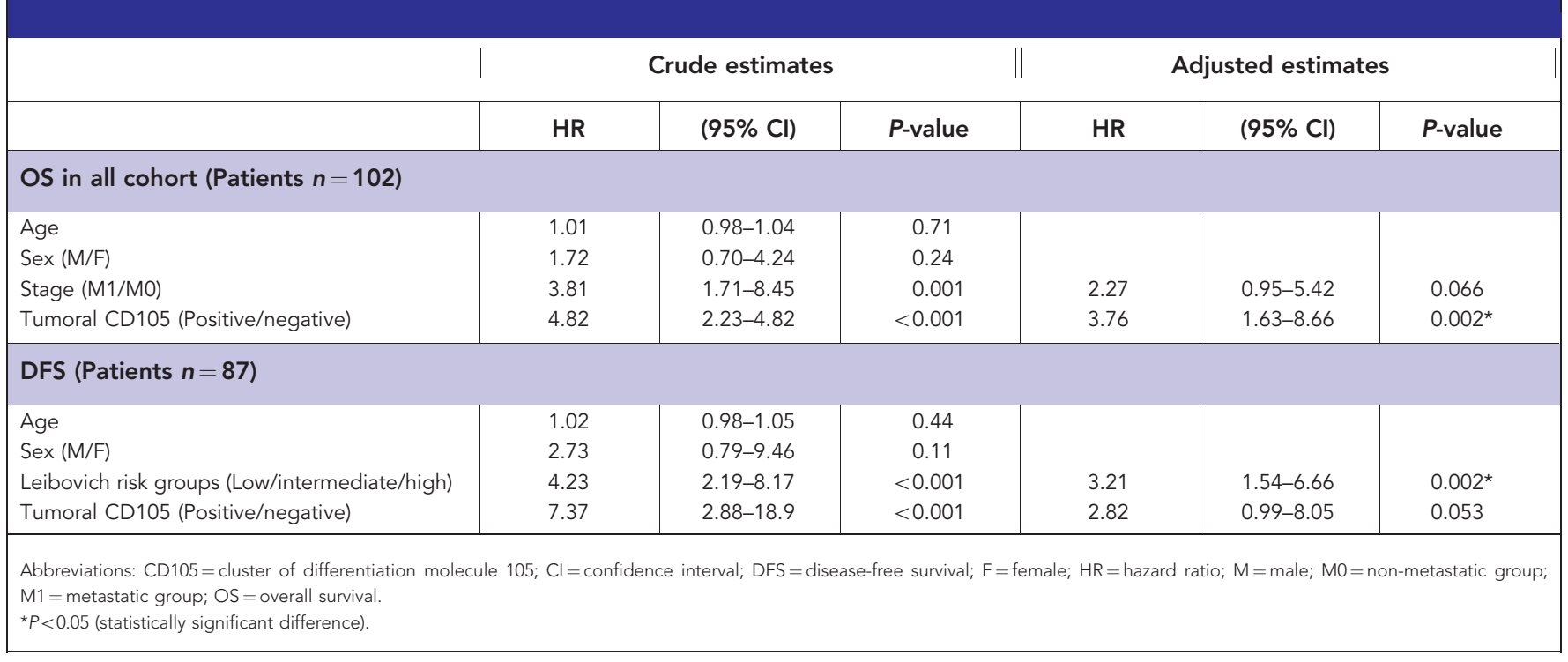

univariate analysis but not reproduced in the multivariate analysis $(P=0.066)$. That is likely due to overfit of the model, because of the low numbers and events. Larger cases or prolonged follow up are still needed. In our cohort, we confirmed the prognostic value of the LS in predicting the DFS in M0 both in univariate $(P<0.001)$ and multivariate analyses $(P<0.001$ with endothelial $\mathrm{CD} 105$ and $P=0.002$ with tumoral CD105).

Several cancers are now considered to contain small subsets of stem-like cells called tumour-initiating or cancer stem cells. These cells acquire greater capacity for self-renewal, differentiation, antiapoptotic features and anchorage independence and thus can migrate to distant sites to initiate new tumour formation. At present, there is an increasing evidence that cancer stem cells are associated with posttreatment relapse. CD105 has been reported to be a stem cell marker in ccRCC (Bussolati et al, 2008; Grange et al, 2011).

The relationships between the expression of CD105 in tumoral cells and the clinicopathological features of ccRCC are investigated for the first time by our group.

Positive expression of CD105 in tumoral cells was found to be significantly and directly correlated to high-grade tumours, more advanced tumour stages and high LS. In addition, both disease-free and OS rates of patients with positive tumoral CD105 expression were significantly lower $(P<0.001)$ than for patients with negative tumoral CD105 expression.

In the multivariate analysis, tumoral CD105 expression retained the poor prognostic significance for OS ( $\mathrm{HR}=3.76,95 \%$ $\mathrm{CI}=1.63-8.66 ; P=0.002)$ and was associated with shorter DFS with marginal statistical significance $(\mathrm{HR}=2.82,95 \% \mathrm{CI}=$ 0.99-8.05; $P=0.053)$. Thus, tumoral CD105 immunoexpression in paraffin-embedded tissue seems to be useful in stratifying ccRCC patients into two prognostic groups. High mortality and increased invasiveness have been shown in patients expressing tumoral CD105 (DFS median of 21.5 months and OS median of 60.8 months in $\mathrm{M} 0$ ), indicating the possibility of an early tumour cell dissemination. Regarding our results, it seems that high-vessel count alone is not sufficient for tumour cell dissemination evaluation. Tumoral CD105 gives important additional information of the tumour aggressiveness, improving the ability to identify relevant risk groups for relapse and development of metastasis in ccRCC.

This may improve the future possibility for specific treatment of ccRCC. Several studies using mice models have shown that selected 
anti-CD105 $\mathrm{mAb}$ are effective in reducing or suppressing angiogenesis, tumour growth and metastasis (Seon et al, 1997; Takahashi et al, 2001). TRC105, an anti-CD105 mAb, is a novel targeted therapy used in phase-I study in patients with advanced refractory solid tumours. Phase-I clinical studies are currently tested to evaluate TRC105 efficiency in a wide variety of cancer types (Rosen et al, 2012).

In summary, the expression of CD105 in tumoral cells is an independent predictor of death risk and unfavourable prognosis in patients with clear cell RCC. Tumoral CD105 was a predictor of patient's outcomes than other clinicopathological factors. Thus, the ability to qualitatively distinguish between endothelial CD105 and tumoral CD105 may be important in the assessment of tumour prognosis. As a nonsurgical strategy, therapy targeting CD105 cancer stem cells may represent a treatment strategy for clear cell RCC.

\section{ACKNOWLEDGEMENTS}

We thank Pascale Bellaud and Roselyne Viel (Plate-forme d'histopathologie, Biosit, Université de Rennes I) for their technical help.This work was supported by grants from ARC (Association pour la Recherche sur le Cancer) 2012-2013: N SFI20121205624 and Ligue contre le Cancer.

\section{REFERENCES}

Albiges L, Salem M, Rini B, Escudier B (2011) Vascular endothelial growth factor-targeted therapies in advanced renal cell carcinoma. Hematol Oncol Clin North Am 25(4): 813-833.

Bochner BH, Cote RJ, Weidner N, Groshen S, Chen SC, Skinner DG, Nichols PW (1995) Angiogenesis in bladder cancer: relationship between microvessel density and tumor prognosis. J Natl Cancer Inst 87(21): 1603-1612.

Bussolati B, Bruno S, Grange C, Ferrando U, Camussi G (2008) Identification of a tumor-initiating stem cell population in human renal carcinomas. FASEB J 22(10): 3696-3705.

Cohen HT, McGovern FJ (2005) Renal-cell carcinoma. N Engl J Med 353(23): 2477-2490.

Dallas NA, Samuel S, Xia L, Fan F, Gray MJ, Lim SJ, Ellis LM (2008) Endoglin (CD105): a marker of tumor vasculature and potential target for therapy. Clin Cancer Res 14(7): 1931-1937.

Delahunt B, Bethwaite PB, Thornton A (1997) Prognostic significance of microscopic vascularity for clear cell renal cell carcinoma. $\mathrm{Br}$ J Urol 80(3): 401-404.

Derynck R, Feng XH (1997) TGF-beta receptor signaling. Biochim Biophys Acta 1333(2): F105-F150.

Dubinski W, Gabril M, Iakovlev VV, Scorilas A, Youssef YM, Faragalla H, Kovacs K, Rotondo F, Metias S, Arsanious A, Plotkin A, Girgis AH, Streutker CJ, Yousef GM (2012) Assessment of the prognostic significance of endoglin (CD105) in clear cell renal cell carcinoma using automated image analysis. Hum Pathol 43(7): 1037-1043.

Duff SE, Li C, Garland JM, Kumar S (2003) CD105 is important for angiogenesis: evidence and potential applications. FASEB J 17(9): 984-992.

Eisen T, Sternberg CN, Robert C, Mulders P, Pyle L, Zbinden S, Izzedine H, Escudier B (2012) Targeted therapies for renal cell carcinoma: review of adverse event management strategies. J Natl Cancer Inst 104(2): 93-113.

Flanigan RC, Mickisch G, Sylvester R, Tangen C, Van Poppel H, Crawford ED (2004) Cytoreductive nephrectomy in patients with metastatic renal cancer: a combined analysis. J Urol 171(3): 1071-1076.
Fuhrman SA, Lasky LC, Limas C (1982) Prognostic significance of morphologic parameters in renal cell carcinoma. Am J Surg Pathol 6(7): 655-663.

Gougos A, Letarte M (1990) Primary structure of endoglin, an RGDcontaining glycoprotein of human endothelial cells. J Biol Chem 265(15): 8361-8364.

Grange C, Tapparo M, Collino F, Vitillo L, Damasco C, Deregibus MC, Tetta C, Bussolati B, Camussi G (2011) Microvesicles released from human renal cancer stem cells stimulate angiogenesis and formation of lung premetastatic niche. Cancer Res 71(15): 5346-5356.

Hermann PC, Bhaskar S, Cioffi M, Heeschen C (2010) Cancer stem cells in solid tumors. Semin Cancer Biol 20(2): 77-84.

Kumar P, Wang JM, Bernabeu C (1996) CD 105 and angiogenesis. J Pathol 178(4): 363-366.

Li C, Guo B, Wilson PB, Stewart A, Byrne G, Bundred N, Kumar S (2000) Plasma levels of soluble CD105 correlate with metastasis in patients with breast cancer. Int J Cancer 89(2): 122-126.

Minardi D, Lucarini G, Mazzucchelli R, Milanese G, Natali D, Galosi AB, Montironi R, Biagini G, Muzzonigro G (2005) Prognostic role of Fuhrman grade and vascular endothelial growth factor in pTla clear cell carcinoma in partial nephrectomy specimens. J Urol 174(4 Pt 1): 1208-1212.

Minhajat R, Mori D, Yamasaki F, Sugita Y, Satoh T, Tokunaga O (2006) Organ-specific endoglin (CD105) expression in the angiogenesis of human cancers. Pathol Int 56(12): 717-723.

Rosen LS, Hurwitz HI, Wong MK, Goldman J, Mendelson DS, Figg WD, Spencer S, Adams BJ, Alvarez D, Seon BK, Theuer CP, Leigh BR, Gordon MS (2012) A phase I first-in-human study of TRC105 (anti-endoglin antibody) in patients with advanced cancer. Clin Cancer Res 18(17): 4820-4829.

Sandlund J, Hedberg Y, Bergh A, Grankvist K, Ljungberg B, Rasmuson T (2006) Endoglin (CD105) expression in human renal cell carcinoma. BJU Int 97(4): 706-710.

Seon BK, Matsuno F, Haruta Y, Kondo M, Barcos M (1997) Long-lasting complete inhibition of human solid tumors in SCID mice by targeting endothelial cells of tumor vasculature with antihuman endoglin immunotoxin. Clin Cancer Res 3(7): 1031-1044.

Sudarshan S, Karam JA, Brugarolas J, Thompson RH, Uzzo R, Rini B, Margulis V, Patard JJ, Escudier B, Linehan WM (2013) Metabolism of kidney cancer: from the lab to clinical practice. Eur Urol 63(2): 244-251.

Takahashi N, Haba A, Matsuno F, Seon BK (2001) Antiangiogenic therapy of established tumors in human skin/severe combined immunodeficiency mouse chimeras by anti-endoglin (CD105) monoclonal antibodies, and synergy between anti-endoglin antibody and cyclophosphamide. Cancer Res 61(21): 7846-7854.

Vermeulen PB, Gasparini G, Fox SB, Toi M, Martin L, McCulloch P, Pezzella F, Viale G, Weidner N, Harris AL, Dirix LY (1996) Quantification of angiogenesis in solid human tumours: an international consensus on the methodology and criteria of evaluation. Eur J Cancer 32A(14): 2474-2484.

Volpe A, Patard JJ (2010) Prognostic factors in renal cell carcinoma. World J Urol 28(3): 319-327.

Weidner N, Semple JP, Welch WR, Folkman J (1991) Tumor angiogenesis and metastasis-correlation in invasive breast carcinoma. N Engl J Med 324(1): $1-8$.

Wikstrom P, Lissbrant IF, Stattin P, Egevad L, Bergh A (2002) Endoglin (CD105) is expressed on immature blood vessels and is a marker for survival in prostate cancer. Prostate 51(4): 268-275.

Yagasaki H, Kawata N, Takimoto Y, Nemoto N (2003) Histopathological analysis of angiogenic factors in renal cell carcinoma. Int J Urol 10(4): 220-227.

This work is published under the standard license to publish agreement. After 12 months the work will become freely available and the license terms will switch to a Creative Commons AttributionNonCommercial-Share Alike 3.0 Unported License. 